\title{
Chronotropic incompetence and a higher frequency of myocardial ischemia in exercise echocardiography
} Joselina LM Oliveira*1,2,3, Thiago JS Góes ${ }^{\dagger 1}$, Thaiana A Santana ${ }^{\dagger 1}$, Thiago F Travassos ${ }^{\dagger 1}$, Lívia D Teles ${ }^{\dagger 1}$, Fernando D Anjos-Andrade ${ }^{\dagger 1}$, Adão C Nascimento-Júnior ${ }^{\dagger 1}$, Érica O Alves ${ }^{\dagger 1}$, Martha A Barreto ${ }^{\dagger 2}$, José A Barreto-Filho ${ }^{\dagger 1}$, Argemiro D'Oliveira J ${ }^{\dagger 3}$ and Antônio CS Sousa ${ }^{\dagger 1,2}$

Address: ${ }^{1}$ Department of Internal Medicine, Cardiology Division, Federal University of Sergipe, Aracaju, Sergipe, Brazil, ${ }^{2}$ Laboratory of Echocardiography of the São Lucas Hospital, Aracaju, Sergipe, Brazil and ${ }^{3}$ Department of Internal Medicine, School of Medicine, Federal University of the Bahia, Salvador, Bahia, Brazil

Email: Joselina LM Oliveira* - joselinasergipe@ig.com.br; Thiago JS Góes - jthico@ig.com.br; Thaiana A Santana - thaianaa@hotmail.com; Thiago F Travassos - doctortravassos@hotmail.com; Lívia D Teles - livinhateles@hotmail.com; Fernando D Anjos-

Andrade - fernandodiego@globo.com; Adão C Nascimento-Júnior - adaocnj@hotmail.com; Érica O Alves - kicalunes@terra.com; Martha A Barreto - marthabarreto@ig.com.br; José A Barreto-Filho - jose.augusto@sergipenet.com.br; Argemiro D'Oliveira - argemiro@ufba.br; Antônio CS Sousa - acssousa@terra.com.br

* Corresponding author †Equal contributors

Published: 2 November 2007

Cardiovascular Ultrasound 2007, 5:38 doi:10.1 186//476-7/20-5-38
Received: 26 August 2007

Accepted: 2 November 2007

This article is available from: http://www.cardiovascularultrasound.com/content/5/I/38

(c) 2007 Oliveira et al; licensee BioMed Central Ltd.

This is an Open Access article distributed under the terms of the Creative Commons Attribution License (http://creativecommons.org/licenses/by/2.0), which permits unrestricted use, distribution, and reproduction in any medium, provided the original work is properly cited.

\begin{abstract}
Background: Exercise echocardiography (EE) is an established method to diagnose coronary artery disease $(C A D)$. Chronotropic incompetence $(\mathrm{Cl})$ during the $\mathrm{EE}$ may be a marker of myocardial ischemia. The purpose of this investigation was to evaluate the additive value of $\mathrm{Cl}$ during $\mathrm{EE}$ in $\mathrm{CAD}$ diagnosis.

Methods: Between 2000 and 2006, 4042 patients (1900 men with a mean age of $56 \pm$ II years) were evaluated by EE. Based on the heart rate (HR) reached during the exercise test, the subjects were divided into two groups: GI group - 490 patients who failed to achieve $85 \%$ of the maximal age-predicted HR, and G2 group - 3552 patients who were able to achieve $85 \%$ of the maximal age-predicted HR.

Clinical characteristics, left ventricular wall motion abnormalities - wall motion score index (WMSI) - and coronary angiography (CA) were the parameters compared between the two groups.

Results: The left ventricular wall motion abnormalities were more frequent in $\mathrm{G}$ I group than in G2 group ( $54 \%$ versus $26 \% ; \mathrm{P}<0.0000 \mathrm{I})$. WMSI was higher in $\mathrm{GI}$ group than in $\mathrm{G} 2$ group, both at rest $(\mathrm{I} .06 \pm 0.17$ versus $\mathrm{I} .02 \pm 0.09 ; \mathrm{P}<0.000 \mathrm{I})$ and after exercise $(\mathrm{I} .12 \pm 0.23$ versus $\mathrm{I} .04 \pm 0.2 \mathrm{I} ; \mathrm{P}<0.000 \mathrm{I})$.

In GI group, $82 \%$ of the patients with positive EE for myocardial ischemia presented obstructive coronary, compared to $71 \%(P=0.03)$ in $\mathrm{G} 2$ group.

Conclusion: $\mathrm{Cl}$ is associated with a higher frequency of myocardial ischemia during $\mathrm{EE}$, reinforcing the concept that $\mathrm{Cl}$ is a marker of the severity of myocardial ischemia.
\end{abstract}




\section{Background}

Chronotropic incompetence (CI), characterized by an attenuated heart rate (HR) response to exercise, was defined as the failure to achieve $85 \%$ of the maximum age-predicted HR [1] and it is not an uncommon finding during treadmill exercise. Although the underlying mechanism is not well defined, it represents an independent predictor of mortality and incidence of CAD $[2,3]$. The reasons for such an association are not properly explained, although several mechanisms have been proposed, such as: severity of CAD, left ventricular (LV) dilation, parasympathetic hyperactivity, sinus node dysfunction, ischemia and advanced age $[4,5]$.

A recent research analyzed endothelial vasodilator function, inflammatory markers and N-terminal pro-brain natriuretic peptide on patients with and without chronotropic incompetence to exercise test and concluded that patients with impaired chronotropic response to graded exercise had endothelial dysfunction, enhanced systemic inflammation and higher N-terminal pro-brain natriuretic peptide concentrations. These findings may partly explain the mechanism of chronotropic incompetence as a predictor of cardiovascular risk and increased mortality [6].

It has been shown that $\mathrm{CI}$ is an independent predictor of death, even in patients taking drugs that interfere with chronotropism such as beta blockers [7].

The treadmill exercise test (ET) is a noninvasive method and one of the most recommended methods for diagnostic and prognostic evaluation of CAD [8]. However, in clinical practice, CI may limit the value of treadmill exercise to confirm CAD diagnosis which is based on ST segment changes occurring at higher rate [9].

Exercise echocardiography (EE) is a noninvasive method well established for the diagnosis and risk stratification of CAD, especially when left bundle branch block (LBBB), left ventricular overload and pre-excitation syndrome are present [10]. The imbalance between oxygen supply and demand leads to myocardial changes caused by ischemia. These alterations occur in a time sequence of pathophysiological phenomena described by Heyndrickx et al and called "ischemia cascade", which is temporally characterized by heterogeneous perfusion, metabolic changes, diastolic dysfunction, regional dyskinesia, electrocardiographic changes and angina [11]. Therefore, EE is able to detect ischemia alterations earlier than ET. However, the role of EE in patients who fail to achieve $85 \%$ of the maximum age-predicted HR remains not fully explained. We hypothesize that EE may bring a significant contribution to this subgroup of patients, since it is more sensitive than conventional ET and it is also able to detect resting segmental LV changes.

The purpose of the present investigation is to assess the value of exercise echocardiography in diagnosis of coronary artery disease in patients with chronotropic incompetence, considering coronary angiography $(\mathrm{CA})$ as the golden standard.

\section{Methods \\ Patient population}

From December 2000 to November 2006, 4042 consecutive patients with known or suspected coronary artery disease were referred to the Laboratory of Echocardiography at São Lucas Hospital (city of Aracaju, State of Sergipe, Brazil) to undergo EE. The ethical principles that guide human experimentation were carefully observed and informed consent was obtained from all the patients involved in the research. The study was approved by the Ethics and Research Committee of the Federal University of Sergipe.

Exclusion criteria were refusal to participate in the research (12 patients), poor imaging quality ( 80 patients), atrial fibrillation (5 patients) and significant valvular heart disease (15 patients).

For the analysis, patients were divided into two groups: G1 group - 490 patients who failed to achieve $85 \%$ of the maximal age-predicted HR and G2 group - 3552 patients who were able to achieve $85 \%$ of the maximal age-predicted HR.

The presence or absence of symptoms such as typical or atypical angina, risk factors of CAD and the use of medication were registered. Hypercholesterolemia was defined as serum total cholesterol levels higher than $200 \mathrm{mg} / \mathrm{dl}$ (after a 12-hour fasting) and hypertriglyceridemia as serum triglycerides levels higher than $150 \mathrm{mg} / \mathrm{dl}$ (after a 12-hour fasting) or by the use of lipid-lowering agents (vastatins and/or fibrates). Systemic hypertension was considered when blood pressure measurements on upper limb, at rest, were $\geq 140 \times 90 \mathrm{mmHg}$ or by the use of antihypertensive medication. Diabetes mellitus was defined as fasting glucose levels above of $126 \mathrm{mg} / \mathrm{dl}$ or by the use of insulin or oral hypoglycemic agents. Previousmyocardium infarction was defined based on clinical history and/or complementary examinations such as electrocardiogram, echocardiogram and coronary angiography.

Single or combined indications for EE were: assessment of chest pain, preoperative assessment of cardiac risk for non-cardiac surgery, presence of a positive ET for myocardial ischemia in patients without clinical probability of CAD, negative ET for myocardial ischemia in patients 
with clinical probability of CAD, stratification of an already established CAD and risk stratification after myocardial infarction.

All the patients were examined after having a light meal. On the day of the exam, they avoided any excessive physical activity and beta blocker had been discontinued four days before the test. All the investigation was conducted with the individual breathing spontaneously in room air, at a constant room temperature of approximately $20^{\circ} \mathrm{C}$ to $24^{\circ} \mathrm{C}$.

The study consisted of the performance of a complete clinical investigation (history taking and physical examination) followed by a 12-lead electrocardiogram (ECG) and resting echocardiogram. Then, patients underwent exercise treadmill and immediately, another echocardiogram was obtained. CA was indicated for the patients who presented a positive EE for myocardial ischemia.

\section{Exercise echocardiography protocol}

All patients underwent symptom-limited treadmill exercise testing according to the standard Bruce protocol. Heart rate was continuously recorded, and patients were strongly encouraged to reach $>85 \%$ of maximal age-predicted heart rate. Workload was expressed in metabolic equivalents (METS). The exercise was interrupted whenever the maximum age-predicted HR was exceeded or in the presence of the following signs and/or symptoms: chest pain, shortness of breath, muscle fatigue, hypertension (blood pressure $\geq 220 \times 120 \mathrm{mmHg}$ ), hypotension, presyncope and severe arrhythmias. During the test, the individuals were continuously monitored with a threelead ECG.

ET was considered positive for myocardial ischemia if there was a horizontal or down-sloping ST-segment depression, of $\geq 1 \mathrm{~mm}$ for men and $1.5 \mathrm{~mm}$ for women, at $80 \mathrm{~ms}$ after the J point. In the presence of electrocardiographic changes which were suggestive of the left bundle branch block (LBBB), left ventricular hypertrophy, preexcitation syndrome and use of medication (digitalis), the test was considered non-diagnostic [8].

The echocardiographs were performed with Hewlett-Packard/Phillips SONOS 5500 systems. Two-dimensional echocardiograph images were obtained from the parasternal and apical windows at rest and immediately after exercise. Both digitized and videotape-recorded or digital video display (DVD) were used for the interpretation of the studies [12]. Regional wall motion was assessed semi quantitatively by experienced echocardiographers, with level III training, as recommended by the American Society of Echocardiography. Wall motion at rest and with exercise was scored 1 through $5(1=$ normal $)$ according to a 16-segment model [13]. Wall motion score index (WMSI), was determined at rest and peak exercise as the sum of the segmental scores divided by the number of visualized segments. The development of new or worsening wall motion was considered indicative of myocardial ischemia. A wall motion abnormality present at rest and unchanged with exercise was classified as "fixed". Therefore, exercise echocardiography results were defined as abnormal if there was ischemia or fixed wall motion abnormalities [14]. We considered EE fixed ischemia and induced ischemia when WSMI became worse after exercise in patients with previous alterations.

\section{Coronary angiography (CA)}

CA was performed voluntarily in the patients who had a positive EE for myocardial ischemia, using the Judkins technique, preferably via right femoral artery [15]. The angiograms and ventriculograms thus obtained were analyzed by an experienced hemodynamicist from our service, using a quantitative score system. After undergoing the procedure, these patients were divided into six subgroups: a) normal coronary arteries; b) narrow, tortuous coronary arteries; c) myocardial bridge or coronary spasm; d) coronary stenosis between $30-50 \%$; e) coronary stenosis greater than $50 \%$; and f) ejection fraction less than $50 \%$. Patients with stenosis $>50 \%$ were considered with CAD.

\section{Statistical analysis}

Continuous variables were reported as mean \pm standard deviation (SD), and comparisons between groups were based on student $t$ test. Categorical variables were summarized as percentage, and group comparisons were based on the Chi-square test. The logistic regression analyses were used with the aim of analyzing associations of the clinical variables (age, gender, systemic hypertension, dyslipidemia and diabetes mellitus), WM abnormalities and CI. The statistically significant data were considered an alpha error $<0.05$. Statistical analyses were performed using the SPSS 13.0 (SPSS, Chicago, IL).

\section{Results \\ Clinical characteristics}

Of the 4042 patients who underwent EE, 1900 were men with a mean age of $56.5 \pm 11.3$ years. G1 group was constituted of $490(12 \%)$ patients and G2 group of 3552 (88\%). Dyslipidemia, systemic arterial hypertension, diabetes mellitus and familial history of CAD were more frequent $(\mathrm{p}<0.001)$ in $\mathrm{G} 1$ group (Table 1).

Between the groups there were not significant differences on atypical angina. However, regarding the asymptomatic patients, we observed greater frequency for G2 group. The typical angina was higher in frequency in G1 group. Coronary bypass surgery, percutaneous coronary intervention 
Table I: Comparison of the clinical findings in patients of the Group I (GI) and patients of the Group 2 (G2).

\begin{tabular}{|c|c|c|c|}
\hline VARIABLES & GI $n=490(12 \%)$ & G2 n = $3552(88 \%)$ & $\mathbf{P}$ \\
\hline Age (Years) & $60.1 \pm 11.2$ & $56 \pm 11.2$ & $<0.0001$ \\
\hline Gender (M/F) & $222(45 \%) / 268$ (55\%) & I $678(47 \%) / 1874(53 \%)$ & 0.421 \\
\hline $\mathrm{BMI}\left(\mathrm{Kg} / \mathrm{m}^{2}\right)$ & $28.2 \pm 5.0$ & $27.3 \pm 4.5$ & 0.914 \\
\hline Asymptomatic & $101(21 \%)$ & 1191 (33\%) & $<0.0001$ \\
\hline Typical Angina & $88(18 \%)$ & 261 (7\%) & $<0.0001$ \\
\hline Atypical Angina & $301(61 \%)$ & $2100(59 \%)$ & 0.330 \\
\hline Systemic Hypertension & 349 (7I\%) & 1973 (55\%) & $<0.0001$ \\
\hline Dyslipidemia & $376(77 \%)$ & $2468(70 \%)$ & 0.001 \\
\hline Cigarette Smoking & $28(6 \%)$ & $181(5 \%)$ & 0.562 \\
\hline Diabetes Mellitus & $79(16 \%)$ & $356(10 \%)$ & $<0.0001$ \\
\hline Family History of CAD & $308(63 \%)$ & $1912(54 \%)$ & $<0.0001$ \\
\hline Previous Myocardial Infarction & $43(9 \%)$ & 146 (4\%) & $<0.0001$ \\
\hline Coronary Bypass Surgery & 61 (12\%) & $190(5 \%)$ & $<0.0001$ \\
\hline $\mathrm{PCl}$ & $52(11 \%)$ & $191(5 \%)$ & $<0.0001$ \\
\hline Beta Blockers & $167(34 \%)$ & $627(18 \%)$ & $<0.0001$ \\
\hline Calcium Channel Antagonists & $45(9 \%)$ & $190(5 \%)$ & 0.001 \\
\hline Nitrates & $49(10 \%)$ & $123(3 \%)$ & $<0.0001$ \\
\hline LBBB & $17(4 \%)$ & 117 (3\%) & 0.833 \\
\hline
\end{tabular}

GI group: patients who failed to achieve $85 \%$ of the maximal age-predicted HR;

G2 group: patients who were able to achieve $85 \%$ of the maximal age-predicted HR.

$\mathrm{BMI}=$ Body Mass Index;

$C A D=$ Coronary Arterial Disease

$\mathrm{PCl}=$ Percutaneous Coronary Intervention

$\mathrm{LBBB}=$ Left Bundle Branch Block

and carrying previous acute myocardial infarction were related to previous cardiovascular antecedents. All of them had a higher frequency in G1 group than in G2 group, with the exception of the LBBB, which did not have significant statistical difference. The use of beta-adrenergic blockers, calcium channel antagonists and nitrates were more frequent in G1 group than in G2 group (Table 1).

\section{Exercise echocardiography (EE)}

The duration of the ET and the METS were less in the G1 group than in the G2 group. During maximal effort, it showed no significant difference of the systolic blood pressure. The wall motion score index (WMSI) was significantly higher in G1 group at rest and after the exercise (Table 2).

During the exercise, the presence of typical angina was more frequent in the G1 group. ST-segment depression had been observed more frequently in the G2 group. Severe arrhythmias (sustained ventricular tachycardia) occurred more frequently in the G1 group than in the G2 group. The arrhythmias (atrial and ventricular premature complexes) were similar in the 2 groups, as well as the necessity of interruption of the examination due to arterial hypertension (Table 3).

While the G2 group had more normal EE results, the G1 group had more ischemic results (Figure 1). The results of exercise echocardiography were demonstrated as normal, ischemic, fixed ischemic, and fixed and induced in the G1 and G2 groups (Figure 2).

\section{Coronary angiography (CA)}

In G1 group, the CA was performed in 211 patients with positive EE for myocardial ischemia $(80 \%)$, while in G2 group, the CA was performed in 644 patients (70\%).

According to the results (Table 4), it was observed that CAD [see additional file 1] was more frequent in G1 group than in G2 group (Figure 3).

The analyses of independent association of CAD with clinical characteristics (age, gender, systemic hypertension, dyslipidemia and diabetes mellitus), WM abnormality and CI were carried out by means of a logistic regression [see additional file 2]. It demonstrated significant elevated odds ration to WM abnormality, CI, gender, dyslipidemia, diabetes mellitus and age (Table 5).

\section{Discussion}

This study investigated, in a large cohort referred with known or suspected CAD, the hypothesis that there is an association between chronotropic incompetence and wall motion abnormality at rest and/or during exercise. The major findings of the present investigation were: (a) the frequency of WM abnormality evaluated by exercise echocardiography in patients with CI was marked higher than in patients who achieved at least $85 \%$ of the maximal 
Table 2: Hemodynamic changes during the EE in patients: Group I (GI) and Group 2 (G2).

\begin{tabular}{|c|c|c|c|c|}
\hline VARIABLES & G I & G2 & $\mathbf{P}$ & $95 \% \mathrm{Cl}$ \\
\hline Resting Heart Rate & $71.25 \pm 13.1$ & $77.6 \pm 16.0$ & $<0.001$ & $(-7.8--4.85)$ \\
\hline Peak Heart Rate & $118.0 \pm 16.0$ & $158.0 \pm 18.4$ & $<0.0001$ & $(-41.49--38.01)$ \\
\hline $\begin{array}{l}\text { Rest Systolic Arterial } \\
\text { Pressure }\end{array}$ & $130.0 \pm 14.0$ & $128.0 \pm 32.0$ & 0.183 & $(-9.58-5.01)$ \\
\hline $\begin{array}{l}\text { Peak Systolic Arterial } \\
\text { Pressure }\end{array}$ & $175.5 \pm 24.8$ & $189.1 \pm 19.6$ & 0.995 & $(-15.5--11.66)$ \\
\hline $\begin{array}{l}\text { Rest Diastolic Arterial } \\
\text { Pressure }\end{array}$ & $84.8 \pm 38.6$ & $82.9 \pm 11.3$ & 0.832 & $(0.28-3.55)$ \\
\hline $\begin{array}{l}\text { Peak Diastolic Arterial } \\
\text { Pressure }\end{array}$ & $87.0 \pm 11.2$ & $86.7 \pm 9.6$ & 0.484 & $(-0.05-1.32)$ \\
\hline Ejection Fraction & $0.64 \pm 0.085$ & $0.66 \pm 0.065$ & $<0.0001$ & $(-0.25--0.01)$ \\
\hline WMSI, rest & $1.06 \pm 0.17$ & $1.02 \pm 0.09$ & $<0.0001$ & $(0.03-0.05)$ \\
\hline WMSI, after exercise & $1.12 \pm 0.23$ & $1.04 \pm 0.21$ & $<0.0001$ & $(0.06-0.10)$ \\
\hline Duration of the Test & $4.8 \pm 2.4$ & $7.8 \pm 2.8$ & $<0.0001$ & $(-3.29--2.7 I)$ \\
\hline METS & $6.6 \pm 2.2$ & $9.3 \pm 2.9$ & $<0.0001$ & $(-1.67--1.88)$ \\
\hline
\end{tabular}

GI group: patients who failed to achieve $85 \%$ of the maximal age-predicted HR;

G2 group: patients who were able to achieve $85 \%$ of the maximal age-predicted HR.

WMSI $=$ Wall Motion Score Index

METS $=$ Metabolic Equivalents

age-predicted heart rate (54\% versus 26\%; $\mathrm{P}<0.00001$ ) (Figure 1); (b) CI was associated with a higher frequency of the 3 types of ischemic response (Figure 2) and (c) in patients with $\mathrm{CI}$ and with positive EE for myocardial ischemia, $82 \%$ had coronary stenosis greater than $50 \%$, while in $\mathrm{G} 2$ group this value was only $71 \%(\mathrm{P}=0.0018)$ (Table 4).

Patients with CI had the higher frequency of cardiovascular risk factors such as diabetes mellitus, dyslipidemia and hypertension (Table 1), confirming the idea that CI has been associated with a higher cardiovascular risk [5]. The presence of typical angina and severe arrhythmias was more frequent in patients with chronotropic incompetence, demonstrating that $\mathrm{CI}$ is a spectrum of more severe CAD (Table 2, 3).

Nevertheless, ST segment depression was less frequent in patients with CI than in G2 group. Therefore, ST segment deviation is not good parameter to detect myocardial ischemia in CI patients. Moreover, this finding underlies that role of stress echocardiography in patients with CI.
Furthermore, this investigation demonstrated that CI patients had three times more chance of having CAD (Table 5).

$\mathrm{CI}$ is a common finding observed during the accomplishment of treadmill exercise test ( 7 to 15\%) [16,17]. Despite the suggestion that $\mathrm{CI}$ is an independent predictor of cardiovascular risk, it has not been used as a marker of cardiovascular risk yet [18]. The chronotropic response during the physical exercise reflects an extremely complex regulation which is correlated to age, functional capacity, heart rate under rest and autonomic balance [17]. Fukuma et al demonstrated that the baroreflex affects the heart rate response via an autonomic mechanism with depressed baroreflex sensibility [19]. In this research we found 490 $(12 \%)$ patients with CI and we speculated if the baroreflex sensibility could be a possible mechanism to explain this result.

The heart rate recovery after exercise was considered another marker of cardiovascular risk. Reduced vagal activity has been shown to adversely impact mortality.

Table 3: Comparison of the clinical and electrocardiographic findings during Exercise Echocardiography in patients: Group I (GI) and Group 2 (G2).

\begin{tabular}{lccc}
\hline \multicolumn{1}{c}{ VARIABLES } & GI $\mathbf{n}=\mathbf{4 9 0}(\mathbf{I} \mathbf{2} \%)$ & G2 $\mathbf{n}=\mathbf{3 5 5 2 ( 8 8 \% )}$ & P \\
\hline Angina & $81(16 \%)$ & $150(4 \%)$ & $<0.0001$ \\
Blood pressure $\geq 220 \times 120 \mathrm{mmhg}$ & $72(15 \%)$ & $508(14 \%)$ & 0.822 \\
Simple Arrhythmia & $97(20 \%)$ & $822(23 \%)$ & 0.098 \\
Severe Arrhythmia & $20(4 \%)$ & $64(2 \%)$ & 0.001 \\
ST segment changes & $144(30 \%)$ & $1517(43 \%)$ & $<0.0001$
\end{tabular}

GI group: patients who failed to achieve $85 \%$ of the maximal age-predicted HR;

G2 group: patients who were able to achieve $85 \%$ of the maximal age-predicted HR. 


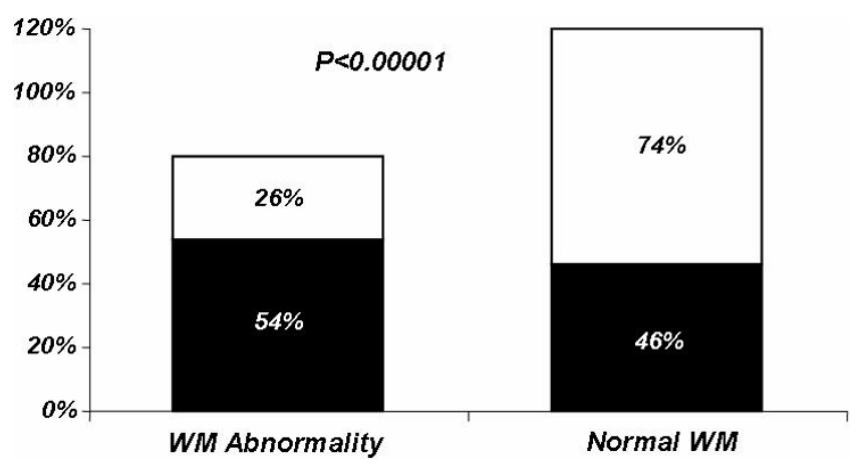

Figure I

WM Abnormality in patients with and without chronotropic incompetence. GI group (black): patients who failed to achieve $85 \%$ of the maximal age-predicted HR; G2 group (white): patients who were able to achieve $85 \%$ of the maximal age-predicted HR.

Although attenuated heart rate recovery had not been helpful in predicting the presence of significant angiographic coronary disease, it predicted mortality [20]. In the present situation it was observed a decrease of the physiological increment of heart rate during exercise. It has been speculated vagal hyperactivity in order to decrease oxygen demand during exercise as a protective anti-ischemic mechanism [21]. This finding is in agreement with the data collected demonstrating that CI was helpful in predicting the presence of more severe coronary disease, although the CI impact in mortality has not been studied.

In addition, Ghaffari et al [22] observed the effect of intravenous atropine on treadmill stress test results on patients with CI. They concluded that the use of atropine as an adjunct to standard exercise stress test can help to decrease the number of non-concluded tests. But broader studies are necessary to define the role of atropine in exercise stress test and also to evaluate the accuracy of conclusive

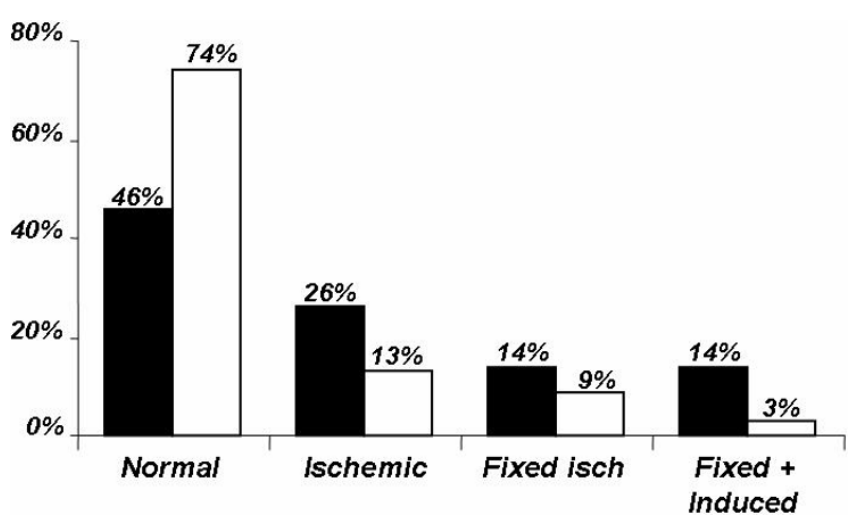

Figure 2

Exercise Echocardiography Results. GI group (black): patients who failed to achieve $85 \%$ of the maximal age-predicted HR; G2 group (white): patients who were able to achieve $85 \%$ of the maximal age-predicted HR.

exercise stress test after atropine administration. Could be interesting speculate if exercise echocardiography wasn't better than atropine on treadmill stress to decreased the number of non-concluded tests.

Many researches had been showed that chronotropic incompetence during physical exercise was a more important predictor of cardiac death than myocardial ischemia evaluated by exercise test, stress echocardiography and PET Scan $[1,3,17,18,23]$. Although we have already had demonstrate that $\mathrm{CI}$ was helpful in predicting the presence of more severe coronary disease, we could to analyze the CI impact in mortality in the next investigate.

This finding of the present study extend our previous one that demonstrated that chronotropic incompetence in patients $\geq 65$ years of age should not be underestimated or deemed physiological because it was associated with higher prevalence of WM abnormalities and, for instance,

Table 4: Comparison between the results of CA in patients with positive EE to myocardial ischemia: Group I (GI) versus Group 2 (G2).

\begin{tabular}{|c|c|c|c|c|}
\hline CA & GI $n=490(12 \%)$ & G2 $n=3552(88 \%)$ & $\mathbf{P}$ & Total \\
\hline Normal & $14(6.6 \%)$ & 72 (। I.2\%) & 0.057 & 86 \\
\hline Coronary Crooked, Fine and with Parietals Injuries & $02(0.9 \%)$ & II (I.7\%) & 0.43 & 13 \\
\hline Myocardium Bridges or Coronary Spasm & $04(1.9 \%)$ & $\mathrm{II}(\mathrm{I} .7 \%)$ & 0.86 & 15 \\
\hline Coronary Stenosis $30-50 \%$ & $12(5.7 \%)$ & $63(9.8 \%)$ & 0.068 & 75 \\
\hline Coronary Stenosis $>50 \%$ & $173(82 \%)$ & $458(71 \%)$ & 0.0018 & 631 \\
\hline Ejection fraction $<50 \%$ & $6(2.8 \%)$ & $28(4.3 \%)$ & 0.33 & 34 \\
\hline Total & $211(100 \%)$ & $644(100 \%)$ & & 855 \\
\hline
\end{tabular}

GI group: patients who failed to achieve $85 \%$ of the maximal age-predicted HR;

G2 group: patients who were able to achieve $85 \%$ of the maximal age-predicted HR. 

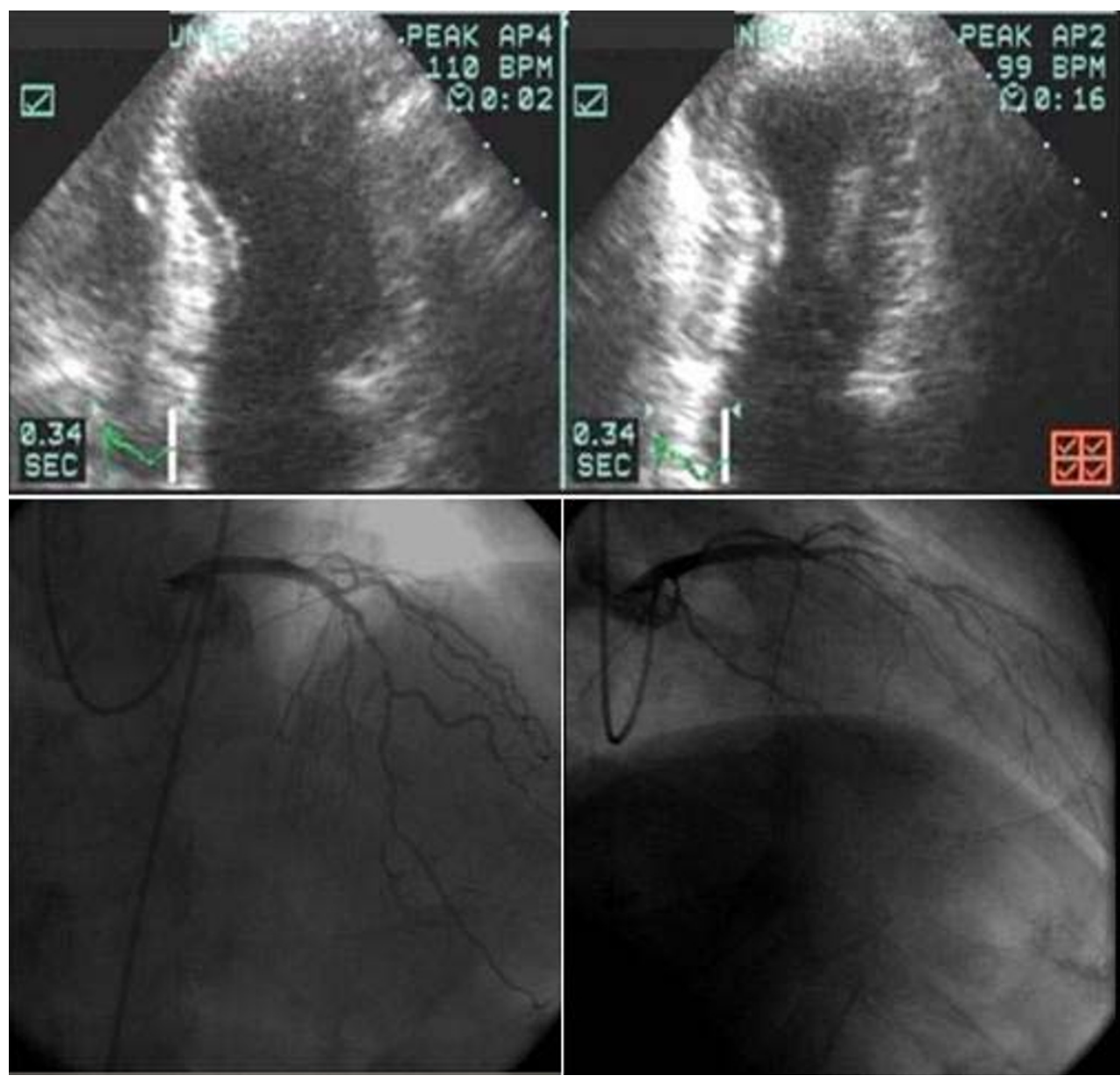

Figure 3

Patient, male, 57 years old with $\mathrm{Cl}(85 \%$ of the maximal age-predicted $\mathrm{HR}=\mathrm{I} 39$ beats per minute). $\mathrm{He}$ achieved $\mathrm{HR}=\mathrm{I} \mathrm{I} 0$ beats per minute. In the $\mathrm{EE}$, akinetic apical septum and hypokinetic antero-apical segment were observed and the $\mathrm{CA}$ demonstrated coronary stenosis greater than $50 \%$.

with myocardial ischemia [24]. Based on the data collected it is suggested that, even in younger patients with suspected CAD, chronotropic incompetence is a marker of more severe CAD.
A limitation of the present study was the fact that the frequency of beta blockers was more prevalent in CI patients. Although the drug had been discontinued four days earlier, its residual effect could not be excluded before the test.

Table 5: Logistic regression analyses of the clinical factors, WM abnormalities and Cl contributing to CAD

\begin{tabular}{lccc}
\hline \multicolumn{1}{c}{ VARIABLES } & OR Crude (IC 95\%) & OR Adjusted IC 95\% & P \\
\hline $\mathrm{Cl}(\mathrm{GI})$ & $3.69(2.99-4.55)$ & $2.62(2.02-3.40)$ & $<0.0000 \mathrm{I}$ \\
WM abnormality & $16.6 \mathrm{I}(13.40-20.6 \mathrm{I})$ & $13.55(10.74-17.09)$ & $<0.0000 \mathrm{I}$ \\
Gender (Male) & $2.80(2.34-3.35)$ & $3.24(2.62-4.0 \mathrm{I})$ & $<0.0000 \mathrm{I}$ \\
Dyslipidemia & $2.39(1.92-2.99)$ & $2.08(1.60-2.69)$ & $<0.0000 \mathrm{I}$ \\
Diabetes Mellitus & $2.68(2.14-3.36)$ & $1.92(1.46-2.54)$ & $<0.0000 \mathrm{I}$ \\
Age & $1.04(1.03-1.04)$ & $1.03(1.02-1.04)$ & $<0.0000 \mathrm{I}$ \\
Hypertension & $1.61(1.32-1.92)$ & $* *$ & 0.053 \\
\end{tabular}

GI group: patients who failed to achieve $85 \%$ of the maximal age-predicted $H R$;

$\mathrm{Cl}=$ Chronotropic Incompetence 


\section{Conclusion}

In summary, through the evaluation of patients for the exercise echocardiography, we suggest that: 1. Exercise echocardiography is a safe and very useful methodology in the evaluation of patients who fail to achieve $85 \%$ of the age-predicted HR; 2 . The chronotropic incompetence, frequently observed during the exercise test, does not have to be underestimated or to be considered as physiological. The data collected suggest that CI is associated with higher frequency of wall motion abnormalities, reinforcing the concept that chronotropic incompetence is a marker of the severity of myocardial ischemia.

Although the CI mechanisms are not elucidated, this investigation suggests that chronotropic incompetence during treadmill should be used as a parameter of cardiovascular risk and not as an inconclusive find.

\author{
Abbreviations \\ $\mathrm{BMI}=$ body mass index \\ $\mathrm{CA}=$ coronary angiography \\ $\mathrm{CAD}=$ coronary artery disease \\ $\mathrm{CI}=$ chronotropic incompetence \\ DVD = digital video display \\ ECG = electrocardiogram \\ $\mathrm{EE}=$ exercise echocardiography \\ $\mathrm{ET}=$ exercise test \\ $\mathrm{HR}=$ heart rate \\ LBBB = left bundle branch block \\ $\mathrm{LV}=$ left ventricular \\ METS = metabolic equivalents \\ PCI = percutaneous coronary intervention \\ $\mathrm{WM}=$ wall motion \\ WMSI = wall motion score index
}

\section{Competing interests}

The author(s) declare that they have no competing interests.

\section{Authors' contributions}

All authors contributed equally to this work, read and approved the final manuscript.

\section{Additional material}

\section{Additional file 1}

Image of CA demonstrated coronary stenosis greater than 50\%. Example of a patient, male, 57 years old, with chronotropic incompetence. The CA demonstrated descendent anterior coronary stenosis greater than $50 \%$. Click here for file

[http://www.biomedcentral.com/content/supplementary/14767120-5-38-S1.jpeg]

\section{Additional file 2}

Logistic regression analyses of the clinical factors, WM abnormalities and CI contributing to CAD - large tables. Data representing the statistical analysis of the factors associated with the diagnoses of CAD.

Click here for file

[http://www.biomedcentral.com/content/supplementary/1476-

7120-5-38-S2.doc]

\section{Acknowledgements}

We thank Doctor Enaldo Vieira de Melo, the biostatistic.

\section{References}

I. Lauer MS, Francis GS, Okin PM, Pashkow FJ, Snader CE, Marwick TH: Impaired Chronotropic Response to Exercise Stress Testing as a Predictor of Mortality. JAMA 1999, 281:565-6.

2. Brener SJ, Pashkow FJ, Harvey SA, Marwick TH, Thomas JD, Lauer MS: Chronotropic response to exercise predicts angiographic severity in patients with suspected or stable coronary artery disease. Am J Cardiol 1995, 76: 1228-32.

3. Lauer MS, Okin PM, Larson MG, Evans JC, Levy D: Impaired heart rate response to graded exercise. Prognostic implications of chronotropic incompetence in the Framingham Heart Study. Circulation 1996, 93:1520-8.

4. Lauer MS, Larson MG, Evans JC, Levy D: Association of left ventricular dilatation and hypertrophy with chronotropic incompetence in the Framingham Heart study. Am Heart J 1999, 137:903-9.

5. Ellestad MH: Chronotropic incompetence. The implications of heart rate response to exercise (compensatory parasympathetic hyperactivity?). Circulation 1996, 93:1485-7.

6. Huang PH, Leu HB, Chen JW, Wu TC, Lu TM, Ding YA, Lin SJ: Comparison of endothelial vasodilator function, inflammatory markers, and $\mathrm{N}$-terminal pro-brain natriuretic peptide in patients with or without chronotropic incompetence to exercise test. Heart 2006, 92:609-14.

7. Khan MN, Pothier CE, Lauer MS: Chronotropic incompetence as a predictor of death among patients with normal electrograms taking beta blockers (metoprolol or atenolol). Am J Cardiol 2005, 96: I 328-33.

8. Gibbons RJ, Balady G], Bricker JT, Chaitman BR, Fletcher GF, Froelicher VF, Mark DB, McCallister BD, Mooss AN, O'Reilly MG, Winters WL, Gibbons RJ, Antman EM, Alpert JS, Faxon DP, Fuster V, Gregoratos G, Hiratzka LF, Jacobs AK, Russel RO, Smith SC, American College of Cardiology/American Heart Association Task Force on Practice Guidelines. Committee to Update the 1997 Exercise Testing Guidelines: ACC/AHA 2002 guideline update for exercise testing: summary article. A report of the American College of Cardiology/American Heart Association Task Force on Practice Guidelines (Committee to Update the 1997 Exercise Testing Guidelines). J Am Coll Cardiol 2002, 40:153 I-40. 
9. Wiens RD, Lafia P, Marder CM, Evans RG, Kennedy HL: Chronotropic incompetence in clinical exercise testing. Am J Cardiol 1984, 54:74-8.

10. Salustri A, Arnese M, Boersma E, Cornel JH, Baptista J, Elhenhy A, ten Cate FJ, de Feyter PJ, Roelandt JR, Fioretti PM: Correlation of coronary stenosis by quantitative coronary arteriography with exercise echocardiography. Am J Cardiol 1995, 75:287-90.

II. Heyndrickx GR, Baig H, Nellens P, Leusen I, Fishbein MC, Vatner SF: Depression of regional blood flow and wall thickening after brief coronary occlusions. Am J Physiol 1978, 234:653-9.

12. Attenhofer CH, Pellikka PA, Oh JK, Roger VL, McCully RB, Shub C, Seward JB: Is review of videotape necessary after review of digitized cine-loop images in stress echocardiography? A prospective study in 306 patients. J Am Soc Echocardiogr 1997, 10:179-184.

13. Schiller NB, Shah PM, Crawford M, DeMaria A, Devereux R, Feigenbaum H, Gutgesell H, Reichek N, Sahn D, Schnittger I, et al.: Recommendations for quantitation of the left ventricle by twodimensional echocardiography. American Society of Echocardiography Committee on Standards, Subcommittee on Quantitation of Two-Dimensional Echocardiograms. J Am Soc Echocardiogr 1989, 2:358-367.

14. Armstrong WF, Pellikka PA, Ryan T, Crouse L, Zoghbi WA: Stress echocardiography: recommendations for performance and interpretation of stress echocardiography. Stress Echocardiography Task Force of the Nomenclature and Standards Committee of the American Society of Echocardiography. J Am Soc Echocardiogr 1998, I I:97-104.

15. Judkins MP: Selective coronary arteriography. I. A percutaneous transfemoral technic. Radiology 1967, 89:815-24.

16. Ellestad MH, Wan MK: Predictive implications of stress testing. Follow-up of 2700 subjects after maximum treadmill stress testing. Circulation 1975, 5 I:363-369.

17. Elhendy A, Mahoney DW, Khandheria BK, Burger K, Pellikka PA: Prognostic significance of impairment of heart rate response to exercise: impact of left ventricular function and myocardial ischemia. J Am Coll Cardiol 2003, 42:823-30.

18. Dresing TJ, Blackstone EH, Pashkow FJ, Snader CE, Marwick TH, Lauer MS: Usefulness of impaired chronotropic response to exercise as a predictor of mortality, independent of the severity of coronary artery disease. Am J Cardiol 2000, 86:602-9.

19. Fukuma N, Oikawa K, Aisu N, Kato K, Kimura-Kato YK, Tuchida T, Mabuchi K, Takano T: Impaired baroreflex as a cause of chronotropic incompetence during exercise via autonomic mechanism in patients with heart disease. Int J Cardiol 2004, 97:503-508

20. Vivekananthan DP, Blackstone EH, Pothier CE, Lauer MS: Heart rate recovery after exercise is a predictor of mortality, independent of the angiographic severity of coronary disease. J Am Coll Cardiol 2003, 42:83I-38.

21. Ferro G, Spinelli L, Duilio C, Spadafora M, Guarnaccia F, Condorelli $\mathrm{M}$ : Diastolic perfusion time at ischemic threshold in patients with stress-induced ischemia. Circulation I991, 84:49-56.

22. Ghaffari S, Sohrabi B: Effect of intravenous atropine on treadmill stress test results in patients with poor exercise capacity or chronotropic incompetence. Saudi Med / 2006, 27: 165-9.

23. Azarbal B, Hayes SW, Lewin HC, Hachamovitch R, Cohen I, Berman DS: The incremental prognostic value of percentage of heart rate reserve achieved over myocardial perfusion single-photon emission computed tomography in the prediction of cardiac death and all-cause mortality: superiority over $85 \%$ of maximal age-predicted heart rate. J Am Coll Cardiol 2004, 44:423-30.

24. Oliveira JL, Góes TJ, Santana TA, Silva IS, Travassos TF, Teles LD, Barreto MA, Barreto-Filho JA, D'Oliveira A Jr, Sousa AC: Exercise stress echocardiography in the identification of coronary artery disease in the elderly with chronotropic incompetence. Arq Bras Cardiol 2007, 89:100-106.

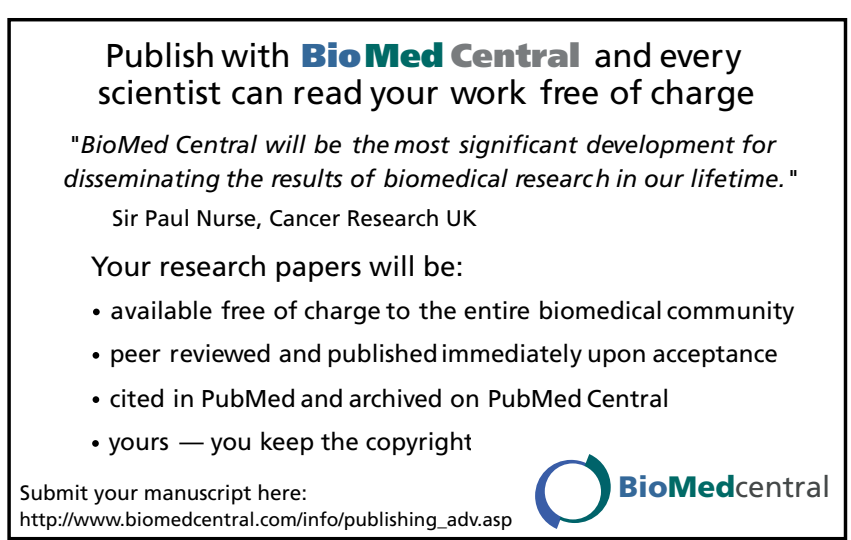

